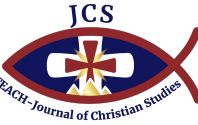

Editorial

\title{
TEACH - JCS Policy
}

Michael Henein, Hany N. Takla and Shereen Azer

The European Academy for Coptic Heritage - TEACH; michael.henein@ teach.eu.com

Submitted: 15 June 2021, accepted: 22 July 2021, published: 21 August 2021

\begin{abstract}
TEACH - Journal of Christian Studies (JCS) is an international peer-reviewed journal dedicated to publishing high quality reports, studies, and review articles covering all aspects of Christian Heritage and Sciences. The journal commissions high quality review articles and editorials from distinguished authors and also welcomes full length original research and review articles, concise reports and letters to the editor. Additionally, JCS aims at publishing well searched controversial issues, with academically balanced evidence-based opinion, consequently establishing a platform for international researchers and scientists to meet and exchange findings, opinions and ideas.
\end{abstract}

How to cite: Henein, M, Takla H and Azer S. TEACH - JCS Policy. TEACH J. Christ. Stud., 2021, 1(1): 1; doi:10.35995/teach-jcs1010001.

(C) 2021 Copyright by the Authors. Licensed as an open access publication under the terms and conditions of the Creative Commons Attribution CC BY 4.0 license.

TEACH - Journal of Christian Studies (JCS) is an international peer-reviewed journal dedicated to publishing high quality reports, studies, and review articles covering all aspects of Christian Heritage and Sciences. The journal commissions high quality review articles and editorials from distinguished authors and also welcomes full length original research and review articles, concise reports and letters to the editor. Additionally, JCS aims at publishing well searched controversial issues, with academically balanced evidence-based opinion, consequently establishing a platform for international researchers and scientists to meet and exchange findings, opinions and ideas. Such platform contents should not be necessarily seen as TEACH - JCS opinion on the subject, unless such opinion is requested and the JCS Editorial Board members accept to provide it supported by the majority of members.

Even for controversial issues that have not been thoroughly researched in the past, JCS is interested in inviting experts in the field to undertake such academic responsibility, i.e., do the necessary research and provide the evidence behind a summary conclusion of the available literature opinion. In addition to the latter, JCS encourages logical thinkers and academic intellects to provide their fair and unbiased opinion about those controversial issues. In doing so, JCS could be seen as an active scientific vehicle that aims at establishing the academic groundwork and scientific findings, supporting them with a contemporary unbiased opinion and delivering it for public benefit. This approach should be seen as a unique channel that aims at enlightening readers and assisting church hierarchies about important congregational issues and in their decision-making process. Such approach is not only limited to the Coptic heritage but all other Christian studies.

At the end of each article, authors should declare any conflict of interest, as the reviewers will also do. If the authors have no conflict of interest, they should add the following statement:

TEACH J. Christ. Stud., 2021, 1(1): 1; doi:10.35995/teach-jcs1010001 
'The authors have no conflict of interest to declare.'

Authors should also mention any funding sources, professional writing services and other significant assistance that could have impacted their academic work, at the end of the above statement. Finally, the following statement must be added at the end of the article:

'The authors agree to abide by the requirements of the "Statement of publishing ethics of the TEACH - Journal of Christian Studies (JCS)'. 